\section{Impact of information and communication technology in a federal teaching hospital library in Nigeria.}

\section{Umar Shuaibu}

Gombe State University, Nigeria

Umar Muhammad Modibbo

Gombe State University, Nigeria

David Danladi

Gombe State University, Nigeria

\section{Mohammed Musa Ibrahim}

Gombe State University, Nigeria
Information Impact:

Journal of Information and Knowledge Management 2017, Vol. 8 (1) Pg. 59 - 65 ISSN: $2141-4297$ (print)

ISSN: 2360 - 994X (e-version) www.informationimpact.org

\begin{abstract}
A special library is an integral part of parent body. The relative contribution made by the special library to the overall success of the parent body cannot be over emphasiszed. The paper discussed the establishment of Federal Teaching Hospital Library Gombe which was popularly known as Federal Medical Centre Gombe. This is an attempt to document the impact of ICT in special libraries with particular reference to the Federal Teaching Hospital Library Gombe
\end{abstract}

Keywords: ICT, hospital libraries, Gombe, teaching hospitals

\title{
Introduction
}

With the coming of the industrial revolution, aroused the need for a working class educated in technology, and industrialists and philanthropies provided facilities and books of elementary technical instruction ( Safra, 2003). The collections of a hospital library also known as special library depend on the specific needs of the organization they served as observed by Halsey et al. (2009). For instance, a hospital may operate a library of materials in the health sciences to serve its doctors and nurses, while a law library firm may maintains its own library of legal documents for use by its lawyers and staff. Special libraries are frequently attached to official institutions such as government agencies, hospitals, museums, a private business organization, religious institutions/ associations. They are planned on strictly practical lines, with activities and collections carefully controlled in size and scope, even though these libraries may be an impact often are large and wide ranging in their activities, they are largely concern with communication information to specialist users in response to or preferably in anticipation of their specific needs. Special libraries have they therefore been much concern with theoretical investigation of information techniques, including the use of computers for indexing and retrieval. 
In addition to performing the same functions as other libraries, Special libraries evaluate, package and present information to users in ways designed to increase productivity and add to the efficiency of their present organizations. They normally achieve these goals by reducing the time that employees spent searching for data and they provide information that facilitate improved decision making. A proper organization of the library is a great asset as stated by Obilade (2003). The ideal Special library attracts prospective users, having regards for the effective service, which it offers. The librarian and other staff members strive hard to determine the information needs of users, and then establish an effective means of communication between the library and the users.

\section{Background information}

The Gombe Federal Teaching Hospital as a parent organization to the library was established in the late 1995, which was formerly called Federal Medical Centre Gombe, operating temporally at the then Gombe state general hospital. After the construction of the hospital, federal medical centre moved to its permanent site in May, 2000. According to Ali (2001), the concept of federal medical centre was rooted in 1981 when the federal government was trying to set out improved tertiary health services by establishing a federal medical centre in each of the states that does not have a teaching hospital. So the one for Gombe, was left on drawing board until about 1995 .

The Federal Teaching Hospital library was established in 2001 to provide library and information services to its teaming community in line with the vision of the hospital which says

Our vision is tertiary health centre that provides excellent, qualitative

and affordable service, training and research to our patients and community with passion and professionalism.

Therefore in order to accomplish the above vision, a professional librarian was employed and later three (3) supporting staff members were employed.

\section{Upgrading the federal teaching hospital library}

The traditional information system in the library has been dependent largely on manual processing and procedures. Since this manual system is no longer very useful in the present "Digital Age" there is the need for the introduction of Information Communication Technology (ICT) into library activities and operations. Eardly (1989) supported this innovation in the library that its introduction will bring about the followings:

- Increase in the types of services offered by the library

- Improved efficiency in terms of time, human resources

- Improved quality of information, in terms of accuracy, level of details, timeless etc.

- Greater flexibility and responsiveness to particular user needs i.e. information system 
may be more readily tailored towards user needs

- Increase efficiency through the sharing of common database either within the same library or externally

- Enhanced degree of user interaction to specific information and processing needs through the review and modification of problems/situations

This benefits are quite enormous, hence the need for Information Communication Technology (ICT) in Nigerian hospital libraries. Nobody can doubt the fact that the world is experiencing information explosion. The amount of information that comes up every day is so vast that it is becoming increasingly more difficult, if not impossible to keep in torch with all current events. The need for devising other means than human ability in handling the multifarious information in our present day special libraries has become necessary. In line with this statement, Corkrane (1992) supported the work of Eardly (1989) by giving the following reasons:

- The failure of the existing traditional method to cope effectively with ever increasing volume in the library

- Allow for easy integration of various activities in the library and

- Increase in library activities i.e. organization and services.

In addition to the above mentioned reasons, application of information communication technologies in special libraries will go a long way in saving staff time and even money. While maintaining greater efficiency on the part of the staff today, information resources are being produced in a combination of texts, graphics, video, audio sounds, animation and virtual reality, special libraries must therefore be ready to handle and utilize them properly to the advantage of their clients.

\section{Impact on Acquisition}

Special libraries have been shifting their focus from ownership to access. Online access to journals, newspapers and other information resources has opened up libraries limited physical collections to an almost limitless set of possibilities. Libraries are turning to consortiums to help negotiate license to access online content. Automation has had several important impacts on acquisitions. Among which are:

1. Reduction of paper and filing cost.

2. Elimination of duplicate orders by checking and on-order file which reduces time, cost and occurrence of error.

3. Access to easy to use currently conversion tables.

4. Management reports to monitor vendor performance.

5. Tools to tract the spending of the library's entire material acquisition budget. 


\section{Impact of ICT on Cataloguing}

The availability of machine-readable catalogue (MARC) records and linking computer terminals using telecommunication has allowed cataloguers to share bibliographic cataloguing records. Among the benefit of information and communication technology in cataloguing includes:

1. Lower cost incurred by substituting paraprofessionals for librarians.

2. More use of copy cataloguing which helps to lower costs.

3. Elimination of card catalogues and their attending filing and maintenance cost.

4. Change in work flow has a big impact on productivity. Minimizing the number of times an item is handled helps reduce cost.

\section{Impact of ICT on Serials}

Managing serials is an important task that can consume significant staff resources in a non automated setting. The ordering, renewal, invoicing, checking in, claims, binding and dealing with cancellations are all processes that require attention and details. While majority of systems support the receipt of journal issues and allow the special library to define a variety of arrival patterns, few systems support the machine-readable catalogue (MARC) format for holdings at both the detail and summary holdings levels.

Among the benefit of automated serials are:

1. Increased control over receipt of issues. This allows the journal issues to get into the hands of the end user sooner. It also allows for more timely and accurate claiming of issues that did not arrive.

2. Production and maintenance of routine lists.

3. Production of local, regional and state serial holding lists.

4. Management report about the usage of each serial title.

\section{Impact of ICT on Circulation}

Information communication technology introduces special libraries to the concept of using barcodes as a way to uniquely identify each item in the collection. Using barcode scanners in the circulation desk speeded up of the check out and checks in process. The net effect of an automated circulation system is improved control over the library's collections and increased staff productivity. Among the benefit noted by several special libraries with automated circulation systems are:

1. No staffing increases are required to cope with increased circulation levels. The improved productivity means that special libraries have not had to increase staff even in the face of increased demand for services. 
Impact of information and communication technology in a federal teaching hospital library in Nigeria.

2. Generating timely overdue notice means faster returns of overdue items. In some cases, special libraries found they had a higher postage cost because overdue notices went out on time rather than being dribbled out using a manual process. Postage costs are reduced with e-mail delivery of overdue and other types of notices.

3. Fines, revenues go up. There is less discussions about special library's fine since the computer tract the check out, renewal and return dates.

4. Items lost through the circulation systems are reduced.

5. Clients are usually able to view their own records, determine the status of a hold request, place a hold and perform other activities remotely by using the library web based OPAC linked to or integrated with the circulation modules.

\section{Impact of ICT on Reference Services}

The major advantages of information and communication technologies to reference service have been identified by Aguolu and Aguolu (2002) as follows:

1. It helps in identification of information relevant to the subject of inquiry.

2. It helps in location of the document or the information itself that is tracking it down to the source through effective bibliographic access control device.

3. It also helps in delivery of located information or record through provision of necessary document delivery mechanisms, ensuring its physical accessibility.

Equally in our own view information and communication technology has its advantages in the library through the following:

1. Easy integration of various activities such as acquisition and bibliographic preparation.

2. Helps in selective dissemination of information (SDI).

3. Increase efficiency.

4. Speedy and easy access to information.

5. Provision of access to unlimited information from different sources.

6. Provision of up to date information.

Above all, one of the benefits of information communication technology in library is instant access to information from multiple sources. Using information communication technology in reference, acquisition and circulation services could be both within and outside the library

\section{The Available ICT Facilities for References Services}

The following have been identified as the Information Communication Technology (ICT) facilities that can be used in the library:

\section{i. The Internet}

The Internet is the biggest global computer network in the world. The Internet otherwise 
known as the information super highway is a massive searchable, dynamic, widely available distributed multi-platform information system that possesses a number of special and general capabilities with bearing on acquisition and reference services. The information practices include www browsing, e-mail, remote access integrated with electronic library and directory services.

\section{ii. Electronic Mail (E-mail)}

Electronic mail allows the exchange of text message between users and the librarians throughout the world. The e-mail is fast and efficient way to exchange information among more than 40 million users in the world.

\section{iii. CD-ROM Searching}

Compact Disk Read Only Memory (CD-ROM) is an information Communication Technology (ICT) facility with great potential for libraries in general. CD-ROM database can hold text, pictures and sound. There are thousands of CD-ROM titles available that are holding variety of information. A good example is the Encyclopedia Britannica with 32 volumes of printed texts stored in 2 CD-ROM. Moreover, CD-ROM application can be found in the area of bibliographical database, full-text journals, newspapers, directories, dictionaries, legal materials and encyclopedias.

\section{Impacts of Electronic Journals}

Today publishers are providing access to the full-text contents of their journals in electronic format, sometimes called e-journals. In some cases, libraries are now eliminating some of their print journals and relying on electronic access. For On-line Public Access Catalogue (OPAC) users, this means that they that they now have the opportunity to do full-searching on the contents of these journals rather than relying solely on citations and abstracts. While the subscription cost per journal titles is less than the printed version, there are a variety of other cost impacts for a library to consider. Typically, access to a specific set of e-journals is bundled with other e-journals, so the library actually increases access to the number of journals for their end user. The net impacts for a library would appear to be mixed, that is, staffing or costs decrease, depending upon the area being considered.

\section{Impacts of ICT on Interlibrary Loan}

While interlibrary loans (ILL) amount to a tiny fraction of library's annual circulation, it is still an important library service. Libraries in North America and Europe loan millions of items annually to other libraries. Rather than requiring a library customer to fill out a manual form that is submitted to a library staff member for review and follow-up action, some libraries have found the patron-initiated interlibrary loan request, using an automated system, provides better service and lower costs. For example, services such as On-line Computer Library Center (OCLC), interlibrary loan module in Ohio United states run by cooperatives have done much to reduce the 
costs associated with providing an interlibrary loan service. The requesting library's ability to identify a lending library, confirm the loan of a book means that the patron receives the desired item much than even 10 years ago.

A special library is an integral part of parent body. The relative contribution made by the special library to the overall success of the parent body can be regarded as the measure of the worth of the library. The primary users of Federal Teaching Hospital, Gombe includes medical and non medical staff of the hospital: doctors, nurses, health workers, clericals, cleaners and securities, all these people need the library to enhance their job performance. Having the above class of workers, it becomes necessary for us to tailor the services of the library to build and improve the goals and mission of the organization.

\section{Conclusion}

In conclusion therefore, the feature of special librarianship is control by the present information technology that is bringing new innovations in library services and activities. All special librarians must adopt the new system for better services in order to move with modern trends of information dissemination services. A special library is expected to procure process, store, retrieve and disseminate information using ICT's in order to meet up with the global trend of information dissemination.

\section{References:}

Agoulu, C.C \& Agoulu, I.E (2002). Libraries and Information Management in Nigeria, Seminar Essays on Themes and Problems. Maduguri: El-inform Service. P 24-30

Ali, G. (2001). FMC Gombe News Bulletin, Vol. 1 (1)

Corkrane, P.A(1992). Information Technology in Libraries and Ranganathan five laws of Library Science. LIBRI, 42(3). PP. 22-26

Eardly, A. (1989). Information System in Development and Operation, Sydney: Longman

Safra (2003). Encyclopedia of Information and Library Science

Usman, I., Abdussalam, H.A. \& Osarome, O. (2008): The Impacts of Information and Communication Technologies in Nigerian Libraries. Abuja Inforlib, Vol. 4(1). PP. 47-53

World Book Encyclopedia (1992). London: World Book International, Vol. 12 